\title{
EPIDEMIOLOGICAL SURVEY OF TRICHINELLA INFECTION IN SOME AREAS OF HENAN Province
}

\author{
BIANLI X., ZAOLIN C., QINGXIA H. \& HUI L.*
}

\section{Summary :}

During 1996-1998 epidemiological survey of domestic Trichinella spiralis infection and serological survey on human beings were carried out in Yanling, Xuchang counties and Luohe city. By the artificial digestion method, the positive rates of pork in market and mutton were $1.6 \%$ and $0.6 \%$ respectively. Meat samples of pigs from pig-farms, cats and dogs were all negative for Trichinella larvae. Trichinellosis infection levels in rats captured in peasant households and places around abattoirs were $0.5 \%$ and $4.1 \%$ respectively $(P<0.05)$. By ELISA (double-antibody) with excretionsecretion (ES) antigens of Trichinella larvae, the positive rates of antibodies against Trichinella in sera of peasants and professional drivers were $2.2 \%$ and $7.8 \%(P<0.05)$. The positive rates of antibodies in pigs from pig-farms and from peasant households were $1 \%$ and $7 \%$ respectively $(P<0.05)$. The levels of antiTrichinella antibodies in rats captured in peasant households and places close to abattoirs were $0 \%$ and $11.1 \%$ respectively. Trichinella spiralis larvae were found in the washing meat slop in abattoirs.

KEY WORDS : trichinellosis, epidemiology, China.

T The trichinellosis endemic areas in China are mainly in three districts: the northeast, the middle part and the southwest of the country. In the latter two endemic areas, the consumption of poorly cooked infected pork is usually the infection route of human trichinellosis and the incidence of trichinellosis in pigs is higher than in other places (1) (Wang Peiren et al., 1997).

But what is the infection source of pig trichinellosis? There are two hypothesis. Firstly, we can hypothesized that pigs drink slop of washing meat, and secondly that they eat rats. These two hypotheses are uncertain or not overall. Thus, during 1996-1998, an epidemiological survey was carried out in Xuchang and Luohe Cities so that a helpful answer could be made and related control measures would be taken in order to block the transmission of trichinellosis.

\footnotetext{
* Henan Provincial Institute of Parasitic diseases, Health and Antiepidemic Centre of Henan Province, 47 Weiwu Road, Zhengzhou, Henan 450003 P.R. China.

Correspondence: Xu Bianli.

Fax:0371-5946322 - e-mail: xubian@public2.zz.ha.cn
}

\section{MATERIALS AND METHODS}

$\mathrm{D}$ ifferent muscle samples were collected: 382 samples from pigs coming from peasant households and 237 from pigs of pig-farms, 74 from dogs, six from cats, 172 from muttons. The weight of each sample was about $20 \mathrm{~g}$ and it was taken on diaphragm pillar. Concerning rats: 386 diaphragm samples were collected on rats captured in peasant households and 73 diaphragm samples came from rats captured in places around abattoirs.

Collection of sera samples: 100 sera samples were taken on pigs from abattoirs, 97 sera samples on pigs from pig-farms, 15 sera samples on rats captured in peasant households and nine sera samples on rats captured close to abattoirs. For human study, 100 sera samples were collected on professional drivers and 23 sera samples on peasants.

In two abattoirs, $1,000 \mathrm{ml}$ slop of washing meat from each abattoir was taken.

Trichinoscopy: $1 \mathrm{~g}$ of muscle from each meat sample described above was cut into pieces and was pressed between two slides before observation on microscope for Trichinella larvae cyst. Rat diaphragm samples were analysed only by this method.

Artificial digestion: $10 \mathrm{~g}$ of muscle from each meat sample described above were digested by artificial digestion solution $\left(1 \% \mathrm{HCl}, 1 \%\right.$ pepsin, $37^{\circ} \mathrm{C}$ for 8 $12 \mathrm{~h}$ ). Through filter and washing, the sediment was observed on miscroscope for Trichinella larvae.

Serological detection: antibodies directed against Trichinella were detected with ELISA by using ES antigens of Trichinella larvae (cut-off value: 0.02-0.3 O.D. units).

\section{RESULTS}

Trichinella cysts were found in some samples of the market pork, mutton and rat muscles whereas all cat and dog samples were negative (Table I). The Trichinella larvae found were identified as Trichinella spiralis by RAPD. Among the 382 sam- 


\begin{tabular}{|c|c|c|c|c|c|c|}
\hline \multirow[b]{2}{*}{$\begin{array}{c}\text { Origin } \\
\text { of meat samples }\end{array}$} & \multicolumn{3}{|c|}{ Trichinoscopy } & \multicolumn{3}{|c|}{ Artificial digestioni } \\
\hline & $\begin{array}{l}\text { Number } \\
\text { of samples } \\
\text { examined }\end{array}$ & $\begin{array}{c}\text { Number } \\
\text { of positive }\end{array}$ & $\begin{array}{c}\text { Positive rate } \\
\text { (\%) }\end{array}$ & $\begin{array}{c}\text { Number } \\
\text { of samples } \\
\text { examined }\end{array}$ & $\begin{array}{c}\text { Number } \\
\text { of positive }\end{array}$ & $\begin{array}{c}\text { Positive rate } \\
(\%)\end{array}$ \\
\hline Pork in market & 382 & 2 & 0.5 & 382 & 6 & 1.6 \\
\hline Pork in piggery & 237 & 0 & 0 & 237 & 0 & 0 \\
\hline Dogs & 74 & 0 & 0 & 74 & 0 & 0 \\
\hline Cats & 6 & 0 & 0 & 6 & 0 & 0 \\
\hline Mutton & 172 & 1 & 0.6 & 172 & 1 & 0.6 \\
\hline Rats in households & 386 & 2 & 0.5 & & & \\
\hline Rats around abattoirs & 73 & 3 & 4.1 & & & \\
\hline
\end{tabular}

Table I. - Meat samples analysis for Trichinella larvae.

ples of market pork, six samples were found positives for cysts by artificial digestion and only two were found to have cysts by trichinoscopy. The infection rates in rats captured in peasant households and those captured around abattoirs were $0.5 \%$ and $4.1 \%$ respectively $(\mathrm{P}<0.05)$.

Antibodies against Trichinella were found in the sera of human, domestic pigs and rats. The positive rate of antibodies in sera of peasants and professional drivers were respectively $2.2 \%$ and $7.8 \%(\mathrm{P}<0.05)$ (Table II). The positive rate in pigs from peasant households and from piggery were $7 \%$ and $1 \%$ respectively $(\mathrm{P}<0.05)$. The positive rate of antibodies in sera of rats captured around households close to abattoirs was higher than that of rats captured in peasant households (Table III). Detection of Trichinella larvae in slop of washing meat: among the two samples of slops, one was found to have two Trichinella larvae and two cysts in meat pieces, the other one was negative (data not shown).

\section{DISCUSSION}

T The analysis of both, meat samples and sera showed that the infection rate of trichinellosis in rats captured in peasant households was much lower than in those captured close to abattoirs. Since we found Trichinella larvae in slop of washing meat in abattoirs, we think that rats are infected by the consumption of this infected slop. In the local area the consumption of meat by peasants is low, thus the chance of rats for eating meat pieces is rare. This can explain the differences in levels of rat-infection between areas close to abattoirs or peasant households. In this survey, among 237 pigs bred in piggery, none were found to be positive for Trichinella, and their positive rate of specific antibodies in sera was low. One of the ways of pig infestation is the consumption of Trichinella-infected rats (Yi Huiming et al., 1987), but around the abattoirs there were often more rats multiplying than around peasant households. Since we

\begin{tabular}{lccc}
\hline $\begin{array}{c}\text { Origin } \\
\text { of sera }\end{array}$ & $\begin{array}{c}\text { Number } \\
\text { of samples } \\
\text { examined }\end{array}$ & $\begin{array}{c}\text { Number } \\
\text { of positive }\end{array}$ & $\begin{array}{c}\text { Positive rate } \\
\text { (\%) }\end{array}$ \\
\hline Peasants & 231 & 5 & 2.2 \\
Drivers & 103 & 8 & 7.8 \\
\hline
\end{tabular}

Table II. - Serological analysis of human sera samples.

\begin{tabular}{lccc}
\hline $\begin{array}{c}\text { Origin } \\
\text { of sera samples }\end{array}$ & $\begin{array}{c}\text { Number } \\
\text { of samples } \\
\text { examined }\end{array}$ & $\begin{array}{c}\text { Number } \\
\text { of positive }\end{array}$ & $\begin{array}{c}\text { Positive rate } \\
\text { (\%) }\end{array}$ \\
\hline Pigs in households & 100 & 7 & 7.0 \\
Pigs in piggery & 97 & 1 & 1.0 \\
Rats in households & 15 & 0 & 0 \\
Rats around abattoirs & 9 & 1 & 11.1 \\
\hline
\end{tabular}

Table III. - Serological analysis of animal sera.

found a higher rate of infestation in pigs from peasant households than from piggery, we think that another way of transmission is also involved in pig infestation. In peasant households, a common habit is to feed pigs with slop of washing meat whereas in piggery the animal food and water are checked for presence of Tricbinella. This difference in pigs feeding can explain the higher rate of Trichinella-infected pigs in peasant households.

In this serological survey, we found $2.2 \%$ of positive rate in peasants. Since they eat less meat than other people and that they are used to cook it well, this explains why they are less infected by Trichinella. In fact, the infection source in peasants is often due to diner with visiting relatives (Xu Bianli et al., 1995). In restaurants, traditional Chinese meals are not cooked enough to kill parasites, thus if the meat is infected a human contamination can occur. The high level of Trichinella infection observed in professional drivers (7.8\%) can be explain by the fact that these people are used to eat often in restaurant comparing to peasant population. 
Official meat inspection of swine has included the obligation to control carcasses for Trichinella larvae. The only official method is trichinoscopy, based on examination of 24 pieces of diaphragm pillars per animal. For bulk production in abattoirs, especially for the low density of Trichinella-positive muscles, a missed detection was often made. For example in this study, among 382 meat samples, six were found to be positive with digestion method whereas only two were positive with trichinoscopy. To avoid missed detection, 2-step digestion method can be recommended (Oivanen et al., 1993), i e. the digestion is performed with pooled samples of diaphragm pillar pieces $(1 \sim 5 \mathrm{~g}$ from each sample). The number of animals pooled in the same digestion assay is determined according to the local infection rate. If the result is positive, the pool is divided in order to identify individualy the infectedanimals.

\section{REFERENCES}

Department of Parasitic Diseases Control, Health and Antiepidemic Station of Yunnan Province. A survey of Trichinella spiralis infection in Yunnan Province. Yunnan Health and Anti-epidemic Journal, 1989, 1, 65-66.

OIVANEN L. \& OKSANEN A. Trichinellosis in domestic swine and wildlife in Finland. Proceedings of the Eighth International Conference on Trichinellosis, Istituto Superiore di Sanita Press, Rome, Italy, 1993, 569-573.

Wang Peiren, Zhang Ding, Yang Hecan \& Ma Luocheng. A survey on Trichinella spiralis infection in pigs in Henan Province. Chinese Zoonosis Journal, 1997, 13 (2), 71-74.

Xu Bianli, Chang Jiang, GaO Guanghan \& Cui Zaolin. Investigative report of four outbreaks of human trichinellosis in Henan. Chinese Medical Journal, 1995, 108 (11), 872875.

Yi Huiming, YANG JinRong \& Jin JunAn. A survey on Trichinella spiralis infection in pigs and rats, with special reference to their relationship. Chinese Preventive Medicine Journal, 1987, 21 (3), 139-141. 